\title{
THE EFFECTS OF MATERNAL PRE-IMMUNIZATION ON PREGNANCY IN THE MOUSE
}

\author{
ANN G. GLARKE \\ Institute of Animal Genetics, West Mains Road, Edinburgh 9
}

(Received 24th April 1970)

\begin{abstract}
Summary. Before mating with males of the $A_{2} G$ or CBA inbred strains of mice, C57BL females were immunized against either the paternal strain antigens (allogeneic) or Peromyscus species antigens (xenogeneic). Evidence is presented which indicates that, contrary to earlier reports, pre-immunization has no effect on placental size, but may reduce foetal weight and litter size. The rôles of specific immunity and non-specific 'stress' are discussed.
\end{abstract}

\section{INTRODUCTION}

During the last 15 years, there have been conflicting reports concerning the effect on pregnancy of maternal pre-immunization against the paternal strain antigens. Several experiments have indicated that pre-immunization does not prejudice foetal survival (Mitchison, 1953; Heslop, Krohn \& Sparrow, 1954; Medawar \& Sparrow, 1956; Woodruff, 1957; Hasková, 1961), whereas Breyere \& Sprenger (1969) and Currie (1969) have provided evidence to the contrary.

There have been suggestions that antigenic differences between the mother and her foetus have an influence on placental and foetal growth (Billington, 1964; James, 1965, 1967). Billington (1965) reported that trophoblastic invasion in an extra-uterine site tended to be greater when transplants were made between two inbred strains of mice than when they were made within strains. Clarke (1969), however, failed to detect any differences in trophoblastic invasion between isogeneic and allogeneic transfers using other strain combinations. Moreover, there was no effect of pre-immunization of the recipients against the donor-strain antigens. James (1967) found that placental and foetal weights in the mouse were increased by immunizing the female to paternal antigens and decreased by rendering her tolerant of them. The present experiments were carried out to re-examine the effect of maternal preimmunization on placental and foetal weights and other aspects of pregnancy.

\section{MATERIALS AND METHODS}

The first experiment utilized the same strain combination as that used by James (1967). In the second experiment, a different paternal strain was used and an additional group of females was immunized xenogeneically to a Peromyscus species. This latter group was included to investigate the effect of a 
general non-specific heightening of the immune response, and the effect of stress experienced by the females during the immunization procedure.

\section{Experiment 1}

C57BL female mice, aged approximately 6 weeks, were divided into three groups. The first group was immunized against $A_{2} G$ male mice either with five spleen-cell injections (a half-spleen equivalent each), or five spleen-cell injections and two skin grafts, or two spleen-cell injections and two skin grafts. All treatments were given at fortnightly intervals. Full thickness skin grafts were applied using the method of Gottfried \& Padnos (1959). The degree of immunity was measured by the human serum dextran technique (Gorer \& Mikulska, 1954). The mice were then weighed, and mated to $A_{2} G$ males. The second group was left untreated but also mated to $A_{2} G$ males. The third group was untreated and mated to C57BL males.

A fourth group of G57BL female neonatal mice was injected with either 5 to 8 million $A_{2} G$ spleen cells or with 16 million $F_{1}$ G57BL female $\times A_{2} G$ male spleen cells to render them tolerant to the paternal strain. Injections were made into the anterior facial vein within $24 \mathrm{hr}$ of birth.

All mice were killed 17 days after the copulation plug was found. Embryos and placentae were removed from the uterus, blotted and weighed to the nearest milligram on a torsion balance. The size of a litter (live foetuses) and the number of deaths during early and middle pregnancy ('moles') were recorded. The reciprocal mating, $\mathrm{A}_{2} \mathrm{G}$ females $\times \mathrm{G} 57 \mathrm{BL}$ males, was not studied.

\section{Experiment 2}

G57BL female mice, aged approximately 10 weeks, received three spleen-cell injections (a half-spleen equivalent each), and two skin grafts from either CBA males or from Peromyscus polionotus polionotus (the deer mouse). A control group was not immunized. All females were mated to GBA males and their embryos were recovered as previously described. This experiment was carried out in a different laboratory from that in which Exp. 1 was conducted and utilized a different population of mice.

\section{Experiment 1}

\section{RESULTS}

The inbred controls had significantly smaller foetuses and placentae than the two outbred groups $(P<0 \cdot 001$; see Table 1$)$; this finding is in agreement with McGarthy (1965) and McLaren (1965). No significant difference was found, however, between the immunized and non-immunized mothers in the

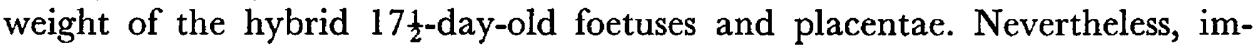
munization appeared to have adverse effects on the outcome of a pregnancy. It significantly decreased the size of a litter $(P<0.01)$ and among those females whose litters contained early and middle deaths ('moles'), there were larger numbers of 'moles' within the immunized mothers $(P<0.05$, Fisher's exact test). The total number of implantations in a litter (live embryos + 'moles') was significantly lower in immunized females than in non-immunized or in inbred controls $(P<0.05$; see Table 2). The number of young in a litter is known to 

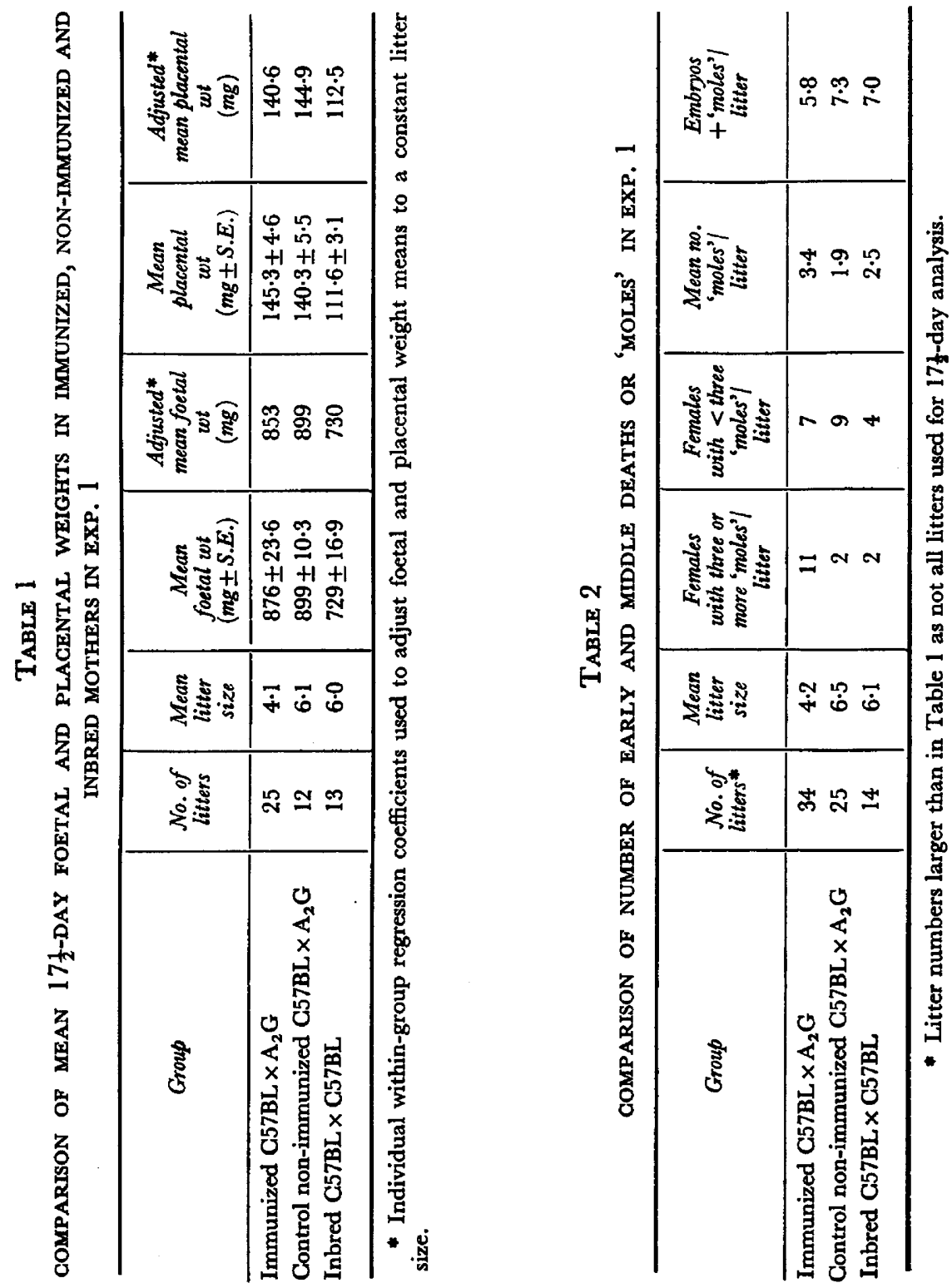

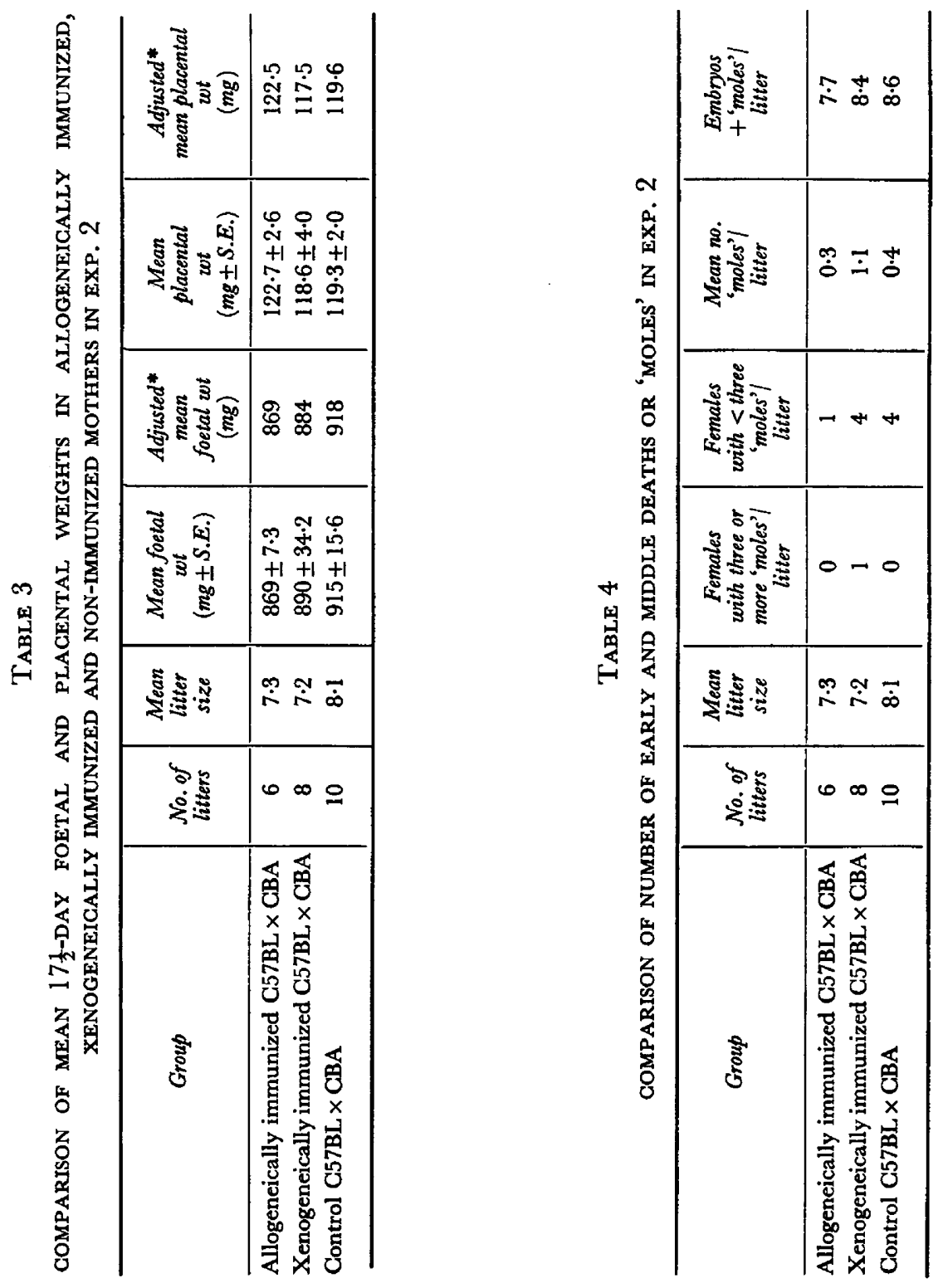
affect placental and foetal weights (Healy, McLaren \& Michie, 1960). Regression analysis allows these weights to be corrected to a standard litter size (5.4 in this case). Regression of foetal weight on litter size $(b=-14.80$; $0 \cdot 1>P>0.05)$ is just below significance but regression of placental weight on litter size is significant $(b=-4.20 ; P=0.01)$. Although the correction for litter size reduces the mean foetal weight of the immunized group where litter sizes were small, the adjusted means of the control and immunized groups are not significantly different $(P>0.05)$. This result is not in agreement with James (1967) who found an increase in placental and foetal weight after maternal immunization. The data in Table 1 show, if anything, a decrease.

The degree of immunity of immunized females as measured by the human serum dextran technique was extremely variable and could not be correlated with the mode of immunization. Haemagglutination titres ranged from 1/16 to 1/16,384. Litter sizes, foetal and placental weights and the number of 'moles' in a litter could not be correlated with the rejection times of the second immunizing skin grafts $(6 \cdot 0 \pm 2$ days), or with the titres of circulating antibody.

Of the forty-eight C57BL female mice that were injected with $A_{2} G$ male spleen cells, all but two developed runt disease. Varying degrees of the typical symptoms (cessation of growth and development, the presence of diarrhoea, sparse hair from about 2 weeks of age) were followed at varying intervals by death. The two survivors received skin grafts at 8 weeks but normal rejection times ( $10 \pm 2$ days) showed the absence of tolerance. The sixty-four neonates receiving $F_{1}$ (C57BL female $\times A_{2} G$ male) spleen cells in an attempt to overcome runt disease also showed no tolerance. Ten individuals grafted with $\mathrm{A}_{2} \mathrm{G}$ male skin at maturity showed rejection times that were normal.

\section{Experiment 2}

The results (Tables 3 and 4) were essentially similar to those of the first experiment. Analysis showed that the mean $F_{1}$ foetal weights from mothers specifically pre-immunized to the paternal antigens were, in this case, significantly smaller than those from control non-immunized mothers $(P<0.02)$. Females immunized against the non-specific antigens of Peromyscus polionotus polionotus gave a mean foetal weight intermediate between the allogeneically immunized and non-immunized groups, but was not significantly different from either of them. Placental weights were similar in all three groups. Although the litter sizes and the total number of implantations were lower in the two immunized groups, the differences were not significant. The overall number of 'moles' was too small for a valid comparison to be made (Table 4). As in Exp. 1, the regression of foetal weight on litter size was not significant $(b=-10.73$; $P>0.05)$ and the regression of placental weight was significant $(b=-2 \cdot 1$; $P<0.05$ ). Correction of foetal and placental weights to a standard litter size of 7.5 reduced the significance of the difference in foetal weight between specifically immunized and non-immunized females $(P=0.05)$.

\section{DISGUSSION}

The results of the two experiments indicate that maternal immunization to 
specific paternal antigens does not enhance placental and foetal growth. Indeed, both experiments show no effect on placental growth but a reduced foetal growth after allogeneic immunization, although this was significant only in Exp. 2. These results therefore conflict with those of James $(1965,1967)$, who found an increase in placental and foetal weight after maternal immunization. Both of the present experiments suggest that immunization reduces litter size, although the effect was significant only in Exp. 1. This was not apparent in the experiments of James, who did not include litters containing less than five young, and litters containing 'moles'. The present findings are in agreement with those of Breyere \& Sprenger (1969) who reported a decreased litter size at birth in G57BL females specifically immunized against DBA/2 sarcoma, and mated to DBA/2 males but no decrease when C57BL females were immunized non-specifically to $\mathrm{C}_{3} \mathrm{H}$ adenocarcinoma. The present findings in Exp. 2 also indicate that non-specific xenogeneic immunization does not reduce foetal weight significantly, but some effect of stress or the raising of a general immune response on foetal weight and litter size cannot as yet be excluded.

Attempts to induce tolerance to $\mathrm{A}_{2} \mathrm{G}$ spleen cells in G57BL female neonates failed because of the occurrence of fatal runt disease (Exp. 1). James (personal communication) found only a $5 \%$ incidence of runt disease in this strain combination using similar doses of spleen cells.

Billingham \& Brent (1959) found the A/G57BL strain combination the least liable to produce tolerance of many strains tested. They obtained low tolerance in the A into G57BL combination and in the reciprocal combination (G57BL into $A$ ), they found $100 \%$ fatal runt disease. The $A_{2} G$ strain was derived about fifty generations ago from the A strain and is unlikely to have acquired many changes at the histocompatibility loci during this time. This has been confirmed by Davies (personal communication) who has typed the histocompatibility loci of the $A_{2} G$ strain and found them similar to the $A$ strain.

G57BL neonates injected with $F_{1}$ (G57BL females $\times A_{2} G$ males) spleen cells should not be capable of responding to the antigens of the $A_{2} G$ strain. Nevertheless, difficulty was experienced in bringing these mice through weaning. Billingham \& Brent (1959) also report reactions to $F_{1}$ cells in the G57/A strain combination.

No satisfactory explanation can be found to account for the difference in the incidence of runt disease between the animals in this study and those of James (1967). The possibility exists that the significantly smaller foetuses and placentae which James obtained from female mice rendered 'tolerant' to the paternal antigens could have been due in part to subclinical runt disease.

\section{AGKNOWLEDGMENTS}

I am greatly indebted to Dr A. McLaren and the late Dr D. R. S. Kirby for their encouragement and advice, to Dr R. Kinsky for help in immunological techniques, to Dr D. A. L. Davies of the Searle Research Laboratory for histocompatibility typing and to Dr B. C. Clarke for statistical advice. The work was supported by the Medical Research Council. 


\section{REFERENCES}

Brzlngham, R. E. \& BRENT, L. (1959) Quantitative studies on tissue transplantation immunity. Phil. Trans. R. Soc. B, 242, 439.

Bulington, W. D. (1964) Influence of immunological dissimilarity of mother and foetus on size of placenta in mice. Nature, Lond. 202, 317.

Billington, W. D. (1965) The invasiveness of transplanted mouse trophoblast and the influence of immunological factors. F. Reprod. Fert. 10, 343.

Breyere, E. J. \& Sprenger, W. W. (1969) Evidence of allograft rejection of the conceptus. Transplantn Proc. 1, 71.

ClaRkE, A. G. (1969) Factors affecting the growth of trophoblast transplanted to the testis. F. Reprod. Fert. 18, 539.

CURRIE, G. A. (1969) The foetus as an allograft: the role of maternal unresponsiveness to paternally derived foetal antigens. In: Foetal Autonomy, pp. 32-52. Ciba Fdn Symp. Churchill, London.

GoRer, P. A. \& MikulskA, Z. B. (1954) Improved methods of antibody detection. Cancer Res. 14, 651.

Gotrfried, B. \& Padnos, M. (1959) A simple rapid method for skin grafting in mice. Transplantn Bull. 6, 427.

Hasková, V. (1961) Relationship between tissues of mother and foetus and tissue incompatibility. Folia biol., Praha, 7, 322.

Healy, M. J. R., Mclaren, A. \& Michie, D. (1960) Foetal growth in the mouse. III. Proc. R. Soc. B, $153,367$.

Heslop, R. W., Krohn, P. L. \& Sparrow, E. M. (1954) The effect of pregnancy on the survival of skin homografts in rabbits. 7. Endocr. 10, 325.

JAMES, D. A. (1965) Effects of antigenic dissimilarity between mother and foetus on placental size in mice. Nature, Lond. 205, 613.

JAMEs, D. A. (1967) Some effects of immunological factors on gestation in mice. F. Reprod. Fert. 14, 265.

McGarthy, J. C. (1965) Genetic and environmental control of foetal and placental growth in the mouse. Anim. Prod. 7, 347.

MaLAREN, A. (1965) Genetic and environmental effects on foetal and placental growth in mice. 7. Reprod. Fert. $9,79$.

MedaWAR, P. B. \& SparRow, E. M. (1956) The effects of adrenocortical hormones, adrenocorticotrophic hormone and pregnancy on skin transplantation immunity in mice. F. Endocr. 14, 240.

Mrtchison, N. A. (1953) The effect on the offspring of maternal immunization in mice. F. Genet. 51, 406.

WoodRUFf, M. F. A. (1957) Transplantation immunity and immunological problems of pregnancy. Proc. R. Soc. B, 148, 68 . 